\title{
Low level cloud motion vectors from Kalpana-1 visible images
}

\author{
Inderpreet Kaur*, S K Deb, C M Kishtawal, P K Pal and Raj Kumar \\ Atmospheric and Oceanic Sciences Group, Space Applications Centre, \\ Indian Space Research Organization, Ahmedabad 380 058, India. \\ *Corresponding author.e-mail: ikaur1985@gmail.com_ikaur@sac.isro.gov.in
}

Till now low-level winds were retrieved using Kalpana-1 infrared (IR) images only. In this paper, an attempt has been made to retrieve low-level cloud motion vectors using Kalpana-1 visible (VIS) images at every half an hour. The VIS channel provides better detection of low level clouds, which remain obscure in thermal IR images due to poor thermal contrast. The tracers are taken to be $15 \times 15$ pixel templates and hence each wind corresponds to about $120 \mathrm{~km} \times 120 \mathrm{~km}$ at sub-satellite point. Multiplet based wind retrieval technique is followed for VIS wind derivation. However, for height assignment of VIS winds, collocated IR image is used. Due to better contrast between cloud and ocean surface, the low level atmospheric flow is captured better as compared to IR winds. The validation of the derived VIS winds is done with Global Forecast System (GFS) model winds and Oceansat-II scatterometer (OSCAT) winds.

\section{Introduction}

Operational derivation of Atmospheric Motion Vectors (AMVs) using successive Infrared (IR) and Water Vapor (WV) channel, geostationary satellite images started in 1970s (Fujita 1968; Hubert and Whitney 1971). Availability of a global network of geostationary satellites and advancing sensor technology has evolved AMV retrieval substantially. Globally AMV observations are routinely derived (Kishtawal et al. 2009; Hongmiong et al. 2010; Oyama 2010; Qisong et al. 2010; Holmlund et al. 2012) by various operational agencies and are used as important input to numerical weather prediction (NWP) models. The assimilation of AMVs shows a significant impact over the low latitudes where winds cannot be inferred from mass fields (Kelly 2004). Also they are particularly very useful over oceanic areas where conventional wind observations are sparse.
Full resolution Visible (VIS) images tracked with high temporal sampling help in capturing additional details of rapidly changing cloud structures. Due to finer resolution and less vulnerability towards attenuation by low level moisture, the cloud features are more discernable in VIS images than IR images. Initially tracking of cloudy features from VIS channel was restricted for studies related to tropical storm analysis. Full resolution VIS images are helpful in tracking slow moving cloud elements associated with the cyclones (Rodgers et al. 1979). Geostationary Meteorological Satellite (GMS) short interval VIS images were used to derive low level winds in the typhoon vicinity (Uchida et al. 1991). Operational derivation of VIS wind over the entire ocean area started with $2.5 \mathrm{~km}$ resolution Meteosat VIS image (Ottenbacher et al. 1997). VIS image tracking provides a better description of the low level flow and also captures the finer circulation features.

Keywords. Atmospheric motion vectors; visible images. 
Presently at European Organization for the Exploitation of Meteorological Satellites (EUMETSAT), both Meteosat first and second generation satellites are used for operational derivation of High Resolution (HR) VIS winds (Holmlund et al. 2012). Korea Meteorological Administration (KMA) utilizes both $1 \mathrm{~km}$ and $4 \mathrm{~km}$ VIS images from Communication, Ocean and Meteorological Satellite (COMS) to produce mesoscale and operational AMVs, respectively (Sohn et al. 2012). Japan Meteorological Agency (JMA) utilizes MTSAT-2 $0.63 \mu \mathrm{m}$ channel to retrieve VIS winds (Hayashi 2012). The VIS channel of Kalpana-1 was not used for wind vector retrieval in the past. It provides much better spatial resolution than the IR channel. The Kalpana-1 VIS channel has a subsatellite point resolution of $2 \mathrm{~km} \times 2 \mathrm{~km}$ with an image frequency of 30 -minute. The main objective of this study is to estimate the low-level winds using Kalpana-1 VIS images. For wind derivation, the low level clouds are tracked over oceans in multiple images and a multiplet based technique (Deb et al. 2012) is used to retrieve the final vector. Due to recent navigational and registration issues with the Kalpana-1 satellite, the main emphasis is given on retrieval from IR equivalent VIS image. Section 2 highlights the automated retrieval procedure adopted for this study, while section 3 gives a validation study of the retrieved winds with the Global Forecast System (GFS) model winds. The retrieved winds are also compared with OceansatII scatterometer (OSCAT) ocean surface winds and finally section 4 concludes the study.

\section{Data and retrieval algorithm}

Kalpana-1 is a geostationary satellite positioned at $72^{\circ} \mathrm{E}$ observing earth with an imaging radiometer in three channels, viz., VIS, IR and WV with central frequency of $0.7,10.5$ and $6.3 \mu \mathrm{m}$, respectively. The temporal resolution of each image is 30 -minute and the spatial resolution is $8 \mathrm{~km}$ for IR and WV channels and, $2 \mathrm{~km}$ for the VIS channel. Due to registration and navigational issues in the full disk Kalpana-1 images, a re-sampled image popularly known as sector generated image (SGP) has been made available for the retrieval community, for all types of wind retrieval. The full disk image is re-sampled over equal longitude and latitude grids at a resolution of $8 \mathrm{~km}$ for all the three channels. Wind retrieval is very sensitive to the changes in the registration hence stressing on the accuracy of the retrieved winds, low resolution (LR) re-sampled VIS image has been used for this study. The results from the HR VIS image have also been discussed briefly in the next section. The
VIS image provides a better contrast for the low level clouds. Low level stratus cannot be easily discerned in IR images due to almost identical surface and cloud radiative temperatures. However, in VIS image, they can be easily identified over darker sea background. The tracking of such clouds is easier in VIS image, resulting in an increase in the number of retrieved vectors and improved accuracies.

The operational IR winds retrieval algorithm is modified to be applied to the re-sampled VIS images. Using VIS images only low level clouds over the oceanic region are tracked and the wind vectors are derived for each half hourly image starting from sunrise to sunset. Wind vectors are also derived over sunlit portions of partial images. The main algorithm comprises of four steps, viz., tracer selection, tracer tracking, wind buffer generation, quality control (Deb et al. 2012) and finally height assignment. The height assignment of visible tracer is done by using collocated IR images. The infrared-window and cloud-base techniques are used for height assignment of derived winds. Each step of retrieval algorithm is briefly summarized as follows:

- Tracer selection: VIS image offers a very good contrast between land and sea, and hence is very useful in tracking low level clouds. But the retrieval is restricted to only oceanic region due to poor contrast between land and clouds over land. To ensure winds are estimated only over ocean, equivalent land mask is used. A $0.25^{\circ} \times 0.25^{\circ}$ land-mask is used to prepare $8 \mathrm{~km}$ land mask. Useful targets are determined over a $15 \times 15$ pixel grid using local image anomaly method (Deb et al. 2008). All target boxes containing land pixels are discarded. Along with it, minimum and mean gray values of each template are used to determine the representative height of the template. This ensures that tracers are limited to low clouds and the sunlit portion of the image.

- Tracer tracking: Each eligible tracer is searched for its best match in a $40 \times 40$ pixel search window centered on the tracer centre in the subsequent image. The level of matching is measured in terms of Nash-Sutcliffe coefficient $E$ (Nash and Sutcliffe 1970).

$$
E=1-\frac{\sum_{i=1}^{n}\left(G_{t}-G_{s}\right)^{2}}{\sum_{i=1}^{n}\left(G_{t}-\bar{G}_{t}\right)^{2}}
$$

where $G_{t}$ and $G_{s}$ represent the gray values for the template and the search window. $\bar{G}_{t}$ represents the average gray values for the template. $n$ defines the size of the template. This technique is advantageous over cross-correlation technique 


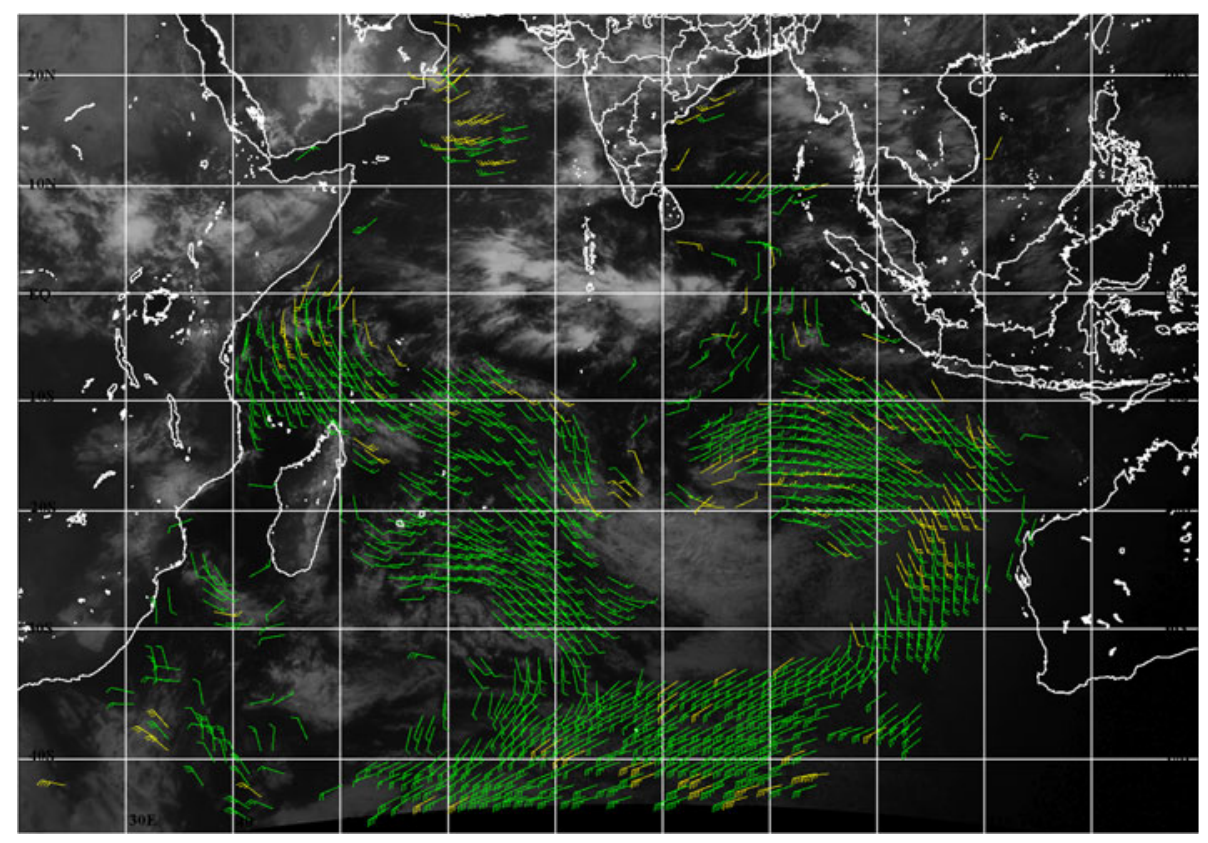

Figure 1. Wind vectors derived from tracking clouds in VIS image on 9 July 2010, 0900 UTC. A total of 1130 vectors are obtained. Green barbs represent pressure levels $800-975 \mathrm{hPa}$ and yellow barbs represent $700-800 \mathrm{hPa}$. A long barb represents 10 knots and a flag 50 knots.

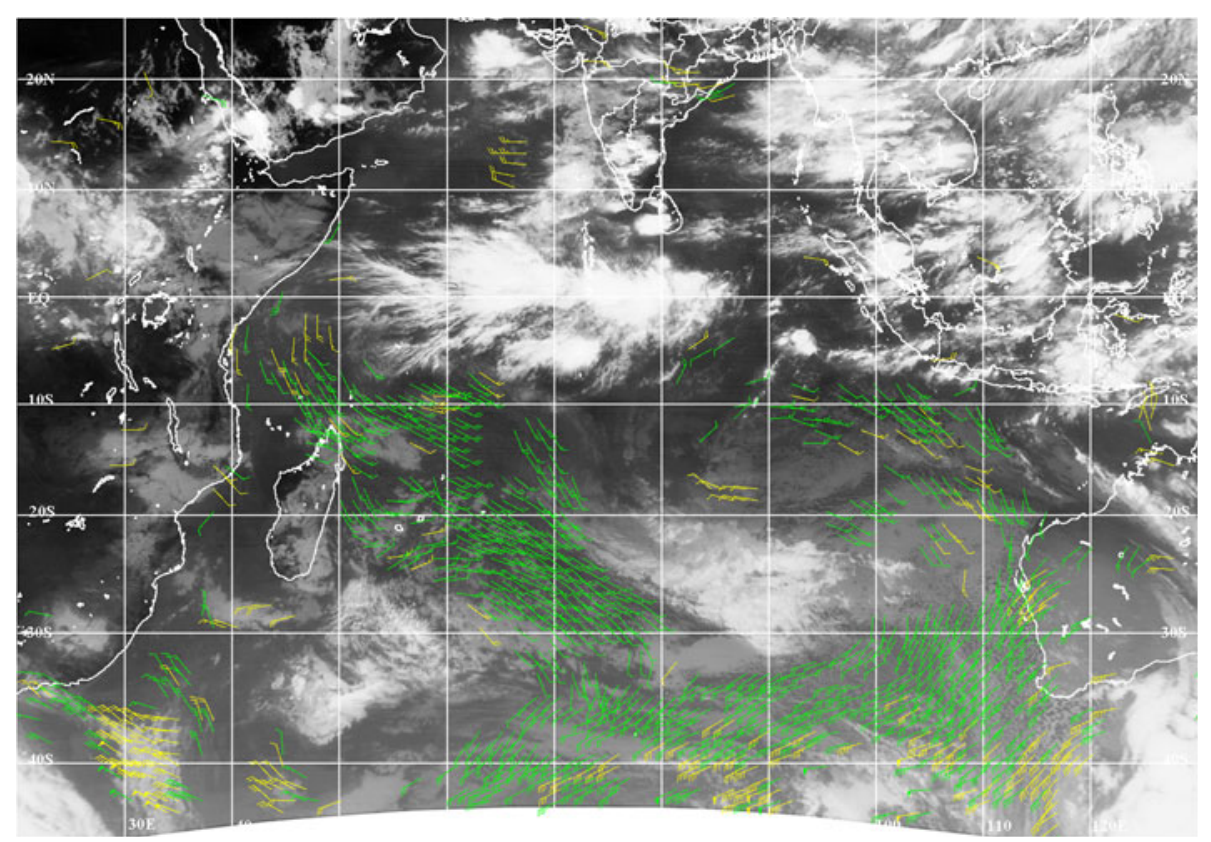

Figure 2. Same as figure 1 but for IR image. A total of 896 vectors are obtained.

as it reduces the possibility of multiple maxima (Deb et al. 2008).

- Wind buffer generation and quality control: In this step of algorithm, a multiplet based technique; where multiple images are used for wind retrieval instead of traditional three images in the triplet based method (Deb et al. 2012) is followed. Here, the information from last eight images is used for quality control. The wind vectors retrieved between each subsequent pair of image $(1-2,2-3,3-4,4-5,5-6,6-7$ and $7-$ 8 ) at each grid point are determined and stored 
Table 1. Validation of Kalpana-1 derived high resolution (HR) VIS winds, low resolution (LR) VIS winds and Meteosat-7 derived HR VIS winds with GFS winds. Normalized RMSVD is dimensionless. All other units are in $\mathrm{m} / \mathrm{s}$.

\begin{tabular}{lccc}
\hline Parameter & $\begin{array}{c}\text { Kalpana-1 HR vs. } \\
\text { GFS winds }\end{array}$ & $\begin{array}{c}\text { Kalpana-1 LR vs. } \\
\text { GFS winds }\end{array}$ & $\begin{array}{c}\text { Meteosat-7 HR vs. } \\
\text { GFS winds }\end{array}$ \\
\hline MVD & 13.71 & 5.24 & 5.11 \\
Normalized RMSVD & 2.05 & 0.76 & 0.46 \\
RMSVD & 14.43 & 5.86 & 5.47 \\
Standard deviation & 3.72 & 2.32 & 1.63 \\
Bias & 3.2 & 0.76 & -0.08 \\
Mean GFS wind speed & 8.68 & 9.78 & 11.91 \\
\hline
\end{tabular}

(a)

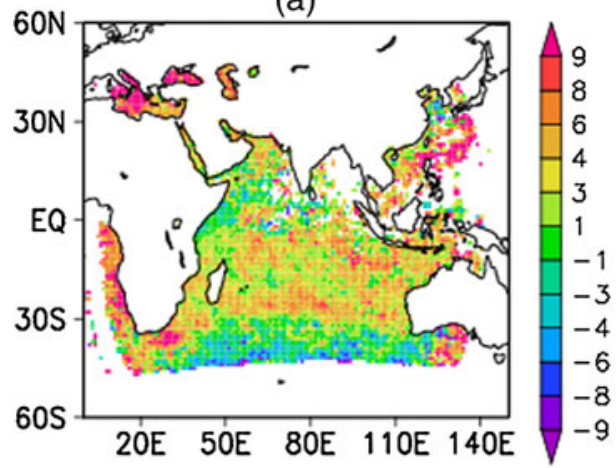

(c)

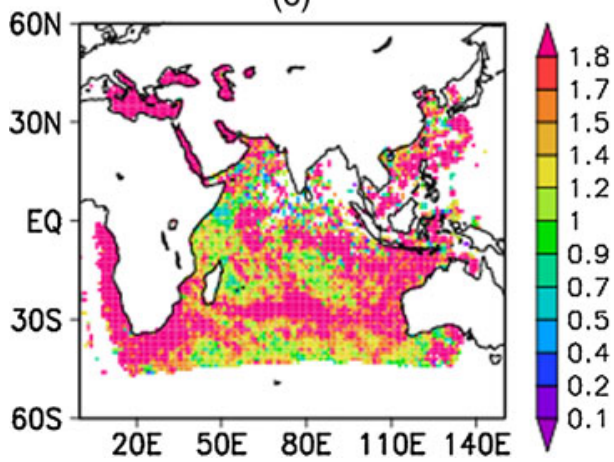

(b)

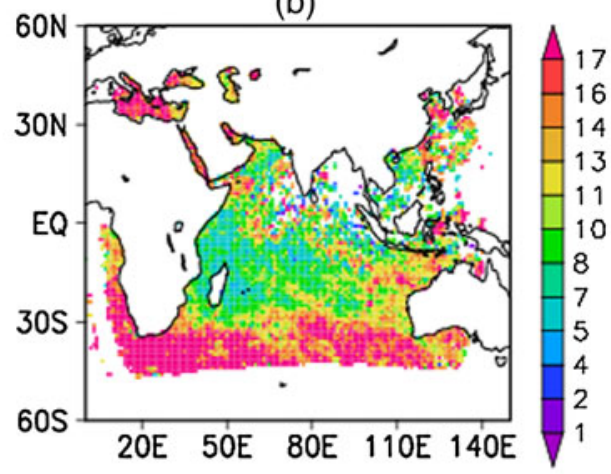

(d)

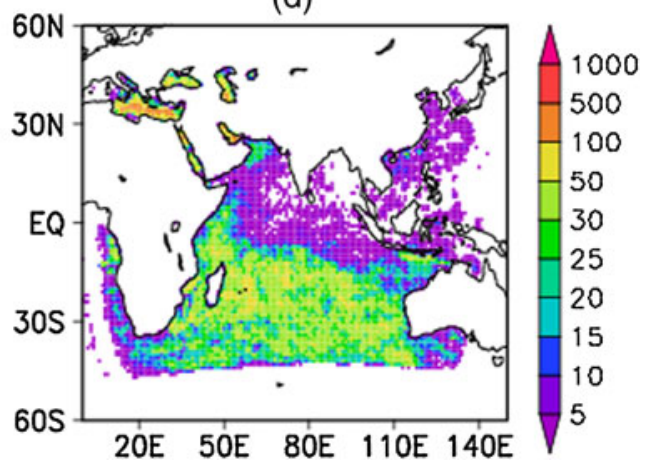

Figure 3. Map plot for Kalpana-1 HR VIS winds vs. GFS winds for July 2010. (a) Bias, (b) MVD, (c) normalized RMS vector difference, and (d) number of collocations.

as buffer in a file. Representing each vector in its complex form $\mathrm{u}+i \mathrm{v}$ (where $i=\sqrt{-1}$ ), vectors with similar brightness characteristics are compared with vectors belonging to a spatial neighbourhood $(i-1, i+1),(j-1, j+1)$ and temporal neighborhood $(t-8, t)$. This method produces a higher number of retrievals over the traditional triplet based algorithm.

- Height assignment: The height assignment of the wind vector derived using VIS imagery is based on equivalent IR channel image. The infraredwindow technique and cloud base technique for infrared tracer height assignment method are used for the collocated VIS cloud tracers. In infrared-window technique, the brightness temperature corresponding to coldest $25 \%$ pixels in a template window is considered and compared with 6-hour forecast model temperature profile to find the level of best fit. The level of best agreement in terms of pressure is taken as the tracer's height. This method works well with opaque clouds which unfortunately are not a good representative of the atmospheric flow. In the cloud base technique (Le Marshall et al. 1993), it 
(a)

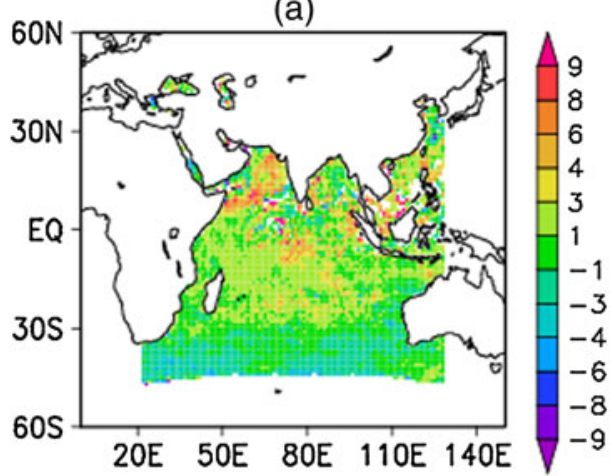

(c)

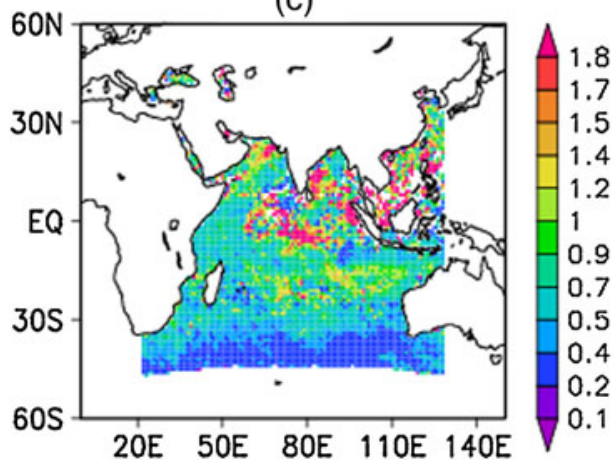

(b)

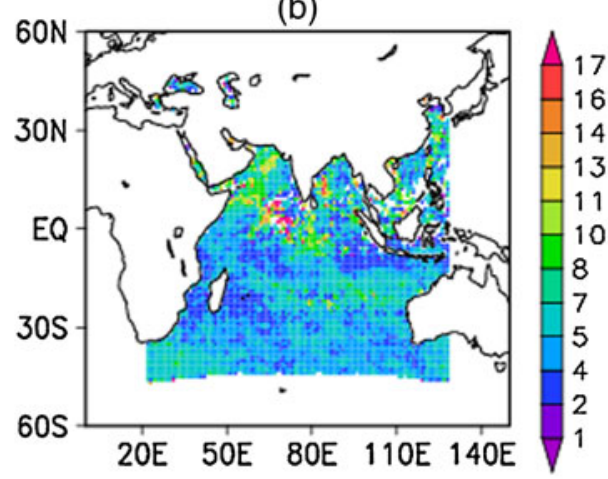

(d)

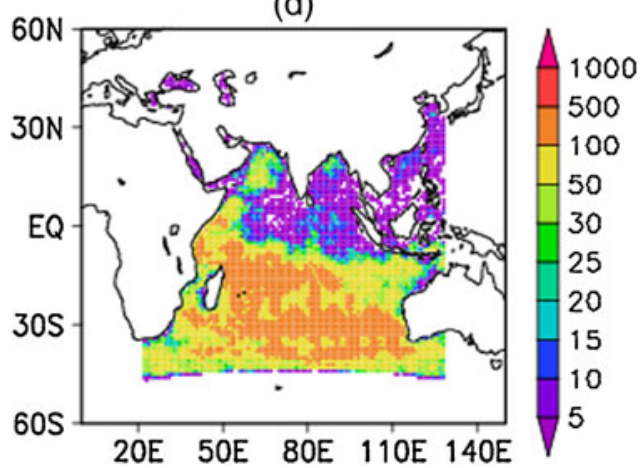

Figure 4. Map plot for Kalpana-1 LR VIS winds vs. GFS winds for July 2010. (a) Bias, (b) MVD, (c) normalized RMS vs. vector difference, and (d) number of collocations.

(a)

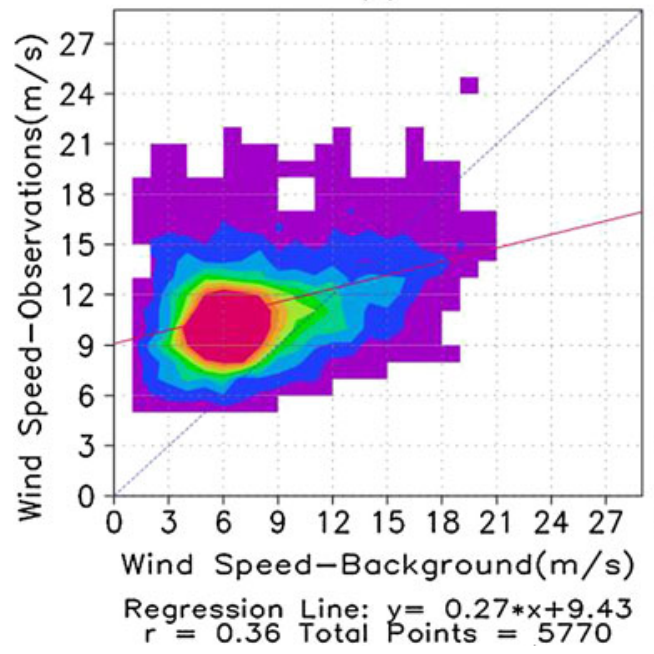

(b)

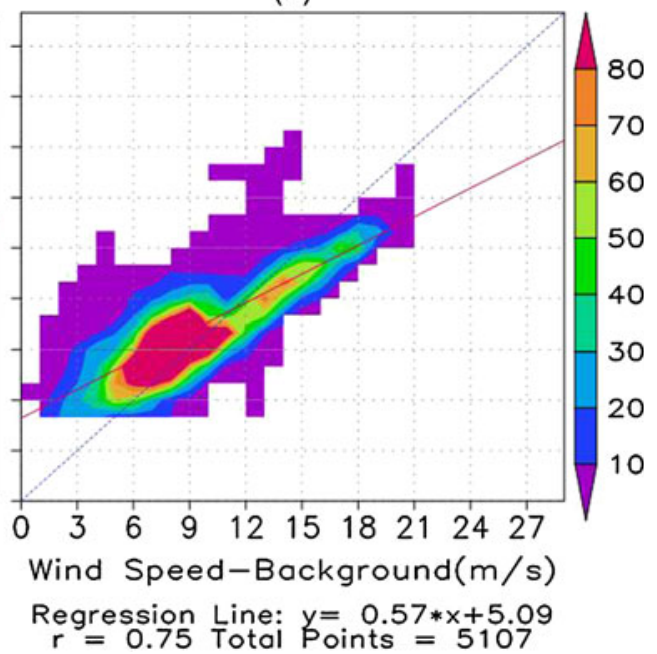

Figure 5. (a) O-B density plot for Kalpana-1 high resolution VIS winds vs. GFS winds, (b) same as (a) but for LR winds.

is assumed that the wind speeds of low level cumulus clouds are best represented by the motion of the cloud base. The histogram of the tracer template window is constructed and using Hermite polynomial, the distribution is separated into cloudy and clear sky components. Second derivative of the cloudy distribution gives the modal cloud temperature and coldest $5 \%$ of cloudy distribution gives the cloud top temperature. The cloud base temperature is located at the same distance from modal cloud temperature as cloud top temperature. The interpolated 6 -hour model forecast temperature is used to convert cloud base temperature to equivalent 
pressure height. The heights of all tracers tracked for wind retrieval are computed by both the methods. All the valid cloud base heights are retained as the final heights. However, if cloud base technique gives a height greater than $600 \mathrm{hPa}$, the height derived using infrared-window technique is used. If both methods give a height greater than $600 \mathrm{hPa}$, then the corresponding vector is discarded.

For validation purpose, OSCAT ocean surface winds (Gohil et al. 2008) and GFS Model winds are used. OSCAT is a $13.5 \mathrm{GHz} \mathrm{Ku}$ Band conically scanning scatterometer system aboard Oceansat2 satellite. OSCAT ocean surface winds represent $10 \mathrm{~m}$ neutral stability winds with a spatial resolution of $50 \mathrm{~km}$. As no radiosonde observations are available over oceans, a rough estimate of VIS wind accuracy is made with OSCAT winds. Weighted averages of OSCAT winds and VIS winds are gridded over $1^{\circ} \times 1^{\circ}$ grids and compared. The temporal window is fixed at \pm 1 hour and all low level winds lying between 850 and $975 \mathrm{hPa}$ are compared with
$10 \mathrm{~m}$ OSCAT winds. GFS is a spectral model with a horizontal resolution of $80 \mathrm{~km}$ (approx.) and 64 vertical levels in sigma coordinate system. $1^{\circ} \times 1^{\circ}$ GFS forecasted wind fields are also used for validation with gridded VIS winds. The temporal window for comparison is fixed at \pm 3 hours. Validation with both OSCAT winds and GFS winds is carried out in accordance with UK Met Office NWP Satellite Application Facility (NWPSAF) guidelines (Forsythe and Doutriax-Boucher 2005). For spatial error plots weighted averages over $0.75^{\circ}$ radius are considered for gridding the winds over $1^{\circ} \times 1^{\circ}$ grids .

\section{Results and discussion}

For this study, VIS-winds are estimated every half hour from sunrise to sunset for the month of July 2010. The maximum vectors are obtained around 0900 UTC, when most parts of Indian Ocean are sunlit. Figure 1 shows an example of the VIS winds derived for 09 UTC of 9 July 2010. In this example,

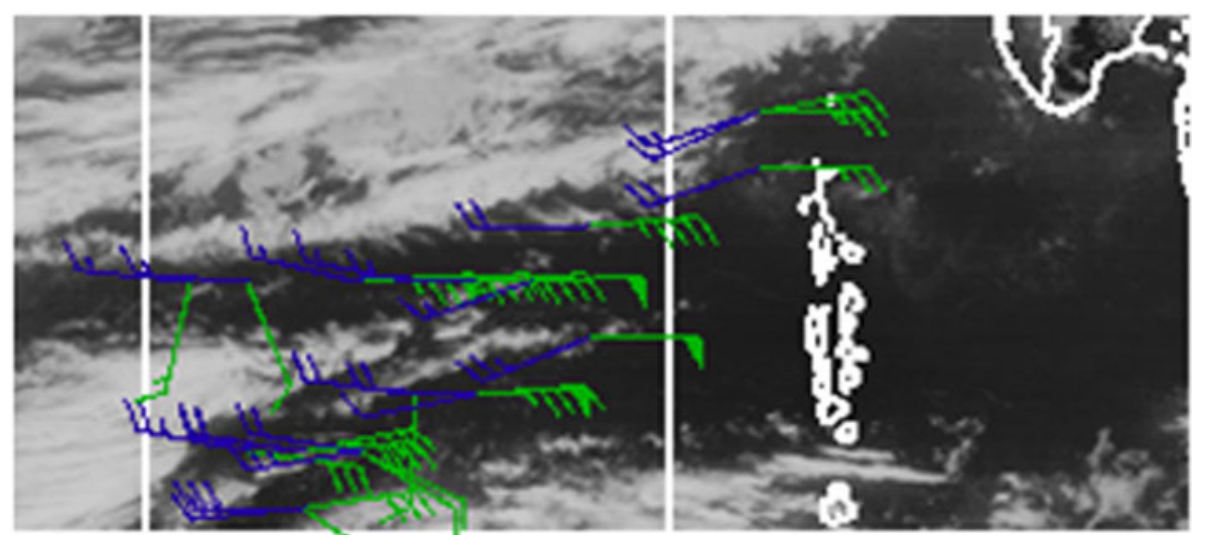

(a)
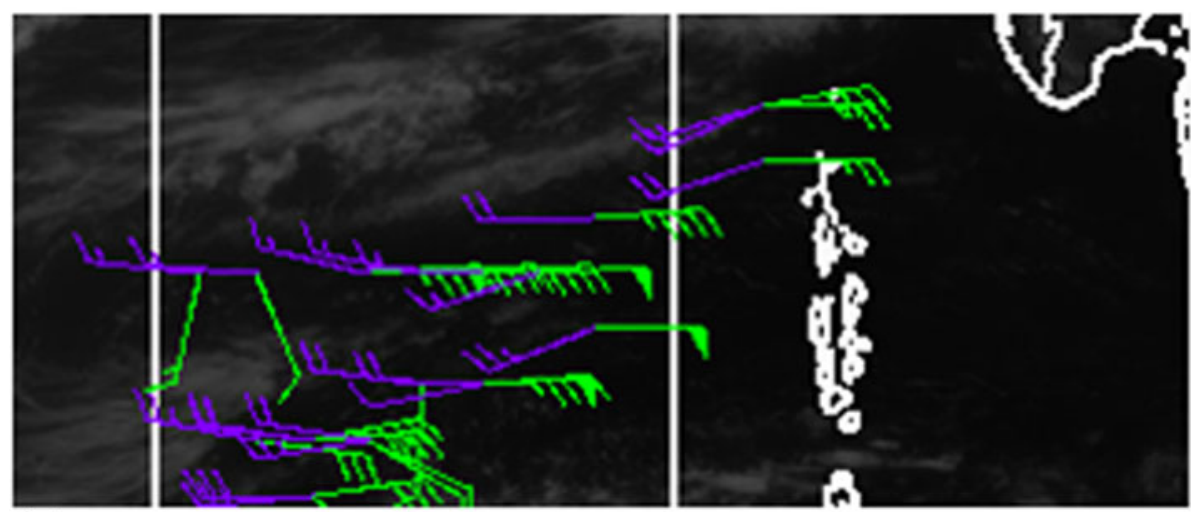

(b)

Figure 6. Collocated Kalpana-1 visible winds and GFS winds for 31 July 2010, 1100 UTC over northern Indian Ocean. These collocations are plotted over (a) IR image and (b) VIS image. Green barbs indicate observations and purple barbs represent collocated model winds. A long barb represents 10 knots and a flag 50 knots. 
a total of 1130 vectors are retrieved in comparison to 896 vectors for the corresponding IR wind using IR images (figure 2). This shows that even with the same resolution of IR and VIS images, more tracers are successfully tracked in the visible image owing to better contrast. The trans-equatorial flow responsible for the low level mass transfer from southern to northern hemisphere is quite prominent in both the channels. But more number of winds are retrieved from the VIS channel especially north of Madagascar where a much stronger flow is captured. The winds $\sim 12-15 \mathrm{~m} / \mathrm{s}$ are observed over the Somali jet. The wind flow south of Indonesia is also more prominent in the VIS winds.

In this study, an attempt for the retrieval of winds from the HR VIS image is also made. The tracking of HR VIS image will produce about 16 times more vectors than LR tracking. But the number of final winds produced is only $25-30 \%$ higher number from the ones yielded by tracking the LR image. In a typical case at 0900 UTC, 9 July 2010, 2412 winds are produced from HR image in comparison to 1677 winds from the LR one. Due to quality issues in the HR images the wind vectors retrieved do not depict the true motion and many vectors are filtered out in the stringent quality control procedure. The number of vectors tracked between two subsequent images prior to quality control is found to be substantially high $\sim 16,000$ but only $1 / 6$ th pass quality check. The quality issues affect the accuracy of the wind vectors as well.

A comparison with the radiosonde observations cannot be made as no data is available over the oceanic region. A few observations available over islands are too less for a reasonable comparison.

Table 2. Validation of Kalpana-1 derived LR VIS winds and Meteosat- 7 derived HR VIS winds with OSCAT winds. Normalized RMSVD is dimensionless. All other units are in $\mathrm{m} / \mathrm{s}$.

\begin{tabular}{lcc}
\hline Parameter & $\begin{array}{c}\text { Kalpana-1 LR vs. } \\
\text { OSCAT winds }\end{array}$ & $\begin{array}{c}\text { Meteosat-7 vs. } \\
\text { OSCAT winds }\end{array}$ \\
\hline MVD & 4.76 & 5.26 \\
Normalized RMSVD & 0.57 & 0.56 \\
RMSVD & 5.23 & 5.57 \\
Standard deviation & 1.84 & 1.37 \\
Bias & 1.78 & 1.33 \\
Mean OSCAT & 9.14 & 9.86 \\
$\quad$ wind speed & & \\
\hline
\end{tabular}

(a)

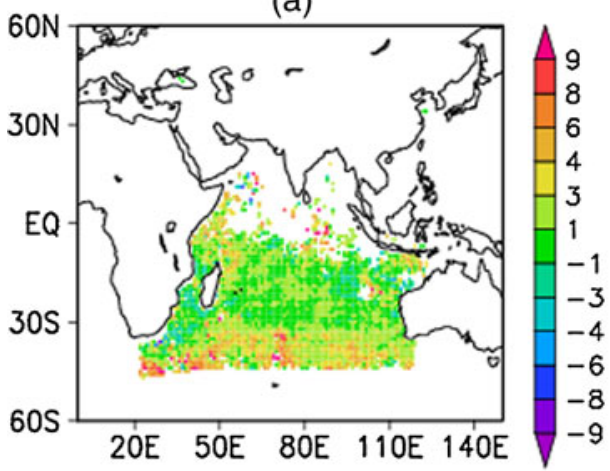

(c)

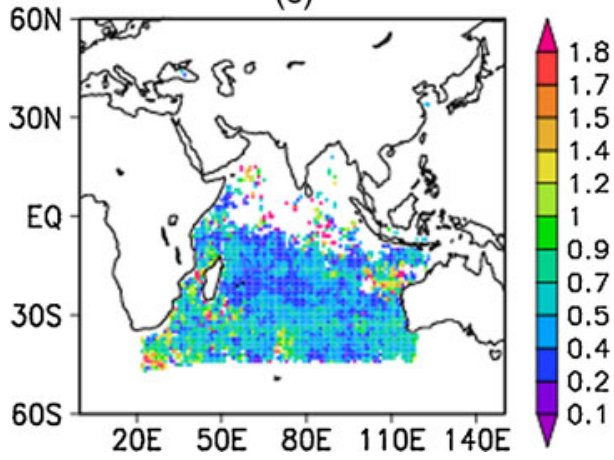

(b)

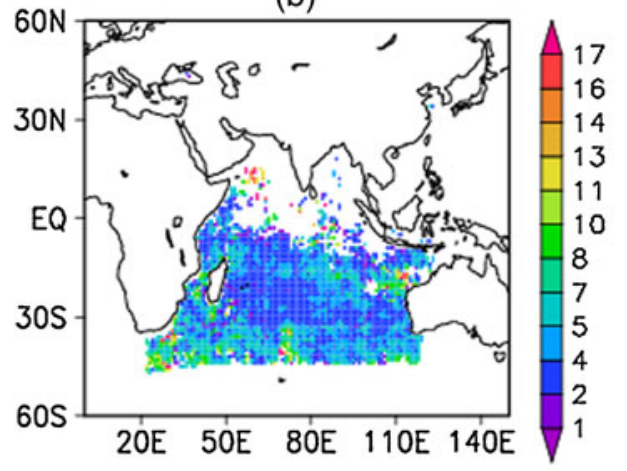

(d)

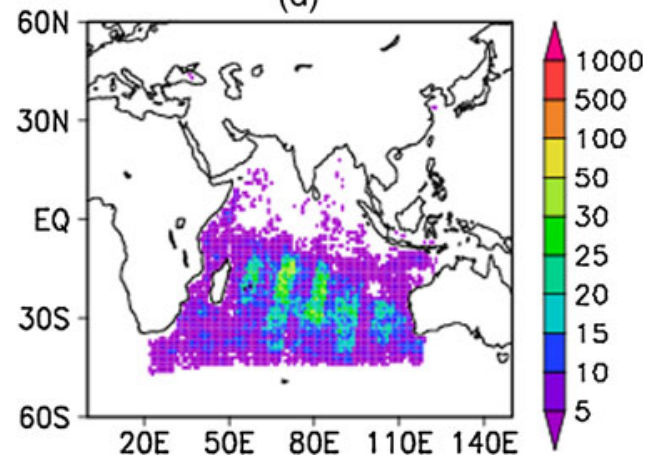

Figure 7. Map plot for Kalpana-1 LR VIS winds vs. OSCAT winds for July 2010. (a) Bias, (b) MVD, (c) normalized RMS vector difference, and (d) number of collocations. 
(a)

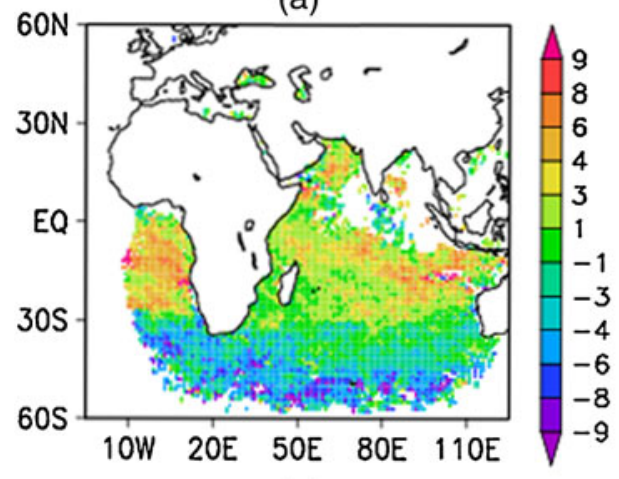

(c)

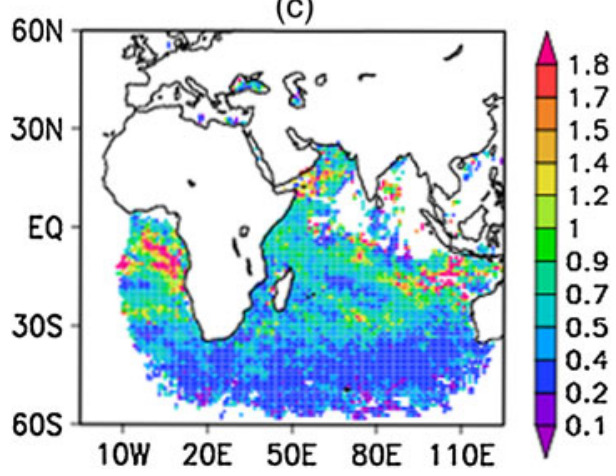

(b)

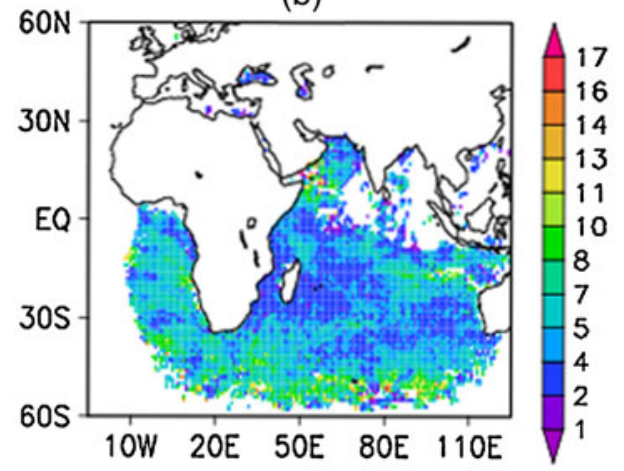

(d)

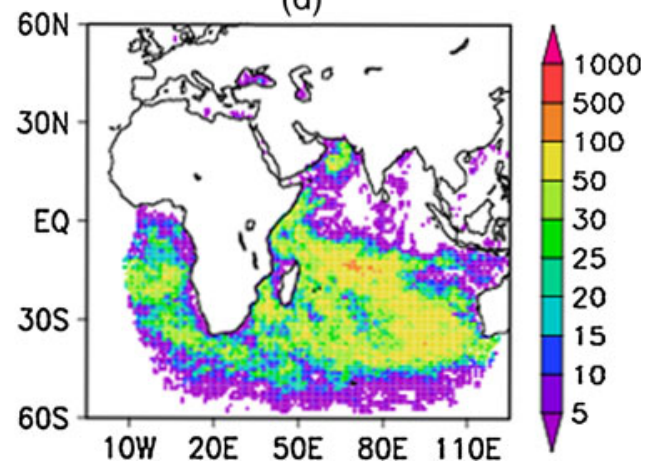

Figure 8. Map plot for Meteosat-7 HR VIS winds vs. GFS winds for July 2010. (a) Bias, (b) MVD, (c) normalized RMS $v s$. vector difference, and (d) number of collocations.

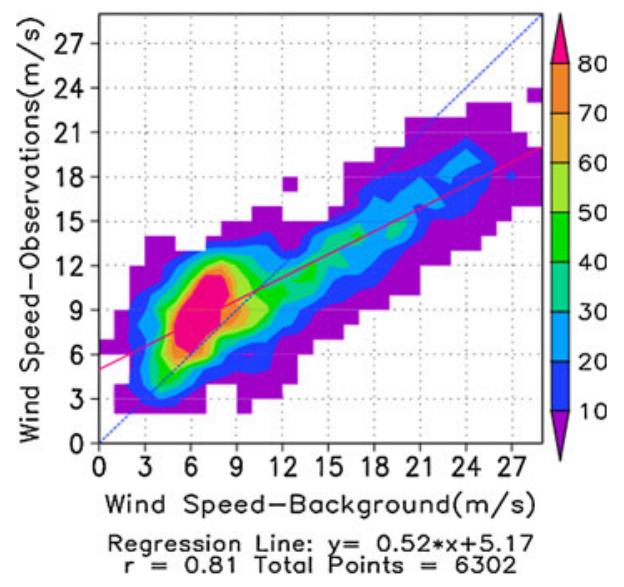

Figure 9. O-B density plot for Meteosat-7 HR VIS winds vs. GFS winds for July 2010.

For the current statistics, retrieved VIS winds are collocated with the GFS winds valid at observation times. Table 1 shows statistics of the comparison when both HR and LR VIS winds are compared with collocated GFS winds. It is seen from the table that HR VIS winds when collocated with GFS winds give a mean vector difference (MVD) of $13.71 \mathrm{~m} / \mathrm{s}$ and a high bias around $3.2 \mathrm{~m} / \mathrm{s}$, while
LR VIS winds give an MVD of $5.55 \mathrm{~m} / \mathrm{s}$ and bias is reduced to $0.86 \mathrm{~m} / \mathrm{s}$. The normalized RMS vector difference (RMSVD) in HR and LR VIS winds are 2.05 and 0.62 , respectively. Figure $3(\mathrm{a}-\mathrm{d})$ shows a spatial plot of error analysis of HR VIS winds when validated with GFS winds. The high MVD $\sim 16-18 \mathrm{~m} / \mathrm{s}$ can be observed at many locations particularly in southern subtropics (figure $3 \mathrm{~b}$ ). It shows that the fast bias exists over the southern Indian Ocean but around $40^{\circ} \mathrm{S}$ large slow bias can also be seen (figure 3a). As is evident from figure 4(a-d), LR VIS winds show better results on validation with GFS winds. The figure $5(\mathrm{a}-\mathrm{b})$ shows the density plots for both the cases. The LR VIS winds (figure 5b) shows better correlation when compared with GFS winds corresponding to HR VIS winds (figure 5a).

It should be noted that both retrieved winds and model forecasts contribute towards the errors and neither can assumed to be true. But closer inspection of the individual observations can separate out the error contributions. The error analysis shows (figure $4 \mathrm{~b}$ ) that MVD over the low level jet is around a low of $2-4 \mathrm{~m} / \mathrm{s}$ but very high values $(15-17 \mathrm{~m} / \mathrm{s})$ are observed southwest of Indian peninsula. The same area shows a marked high bias as well. In an attempt to isolate the reason for high errors, individual cases are considered. 
(a)

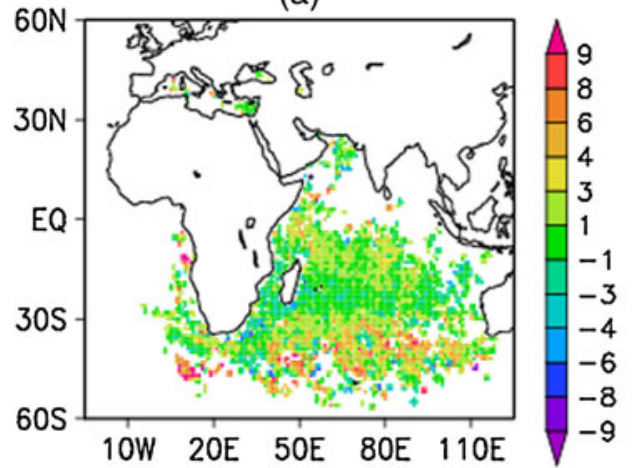

(c)

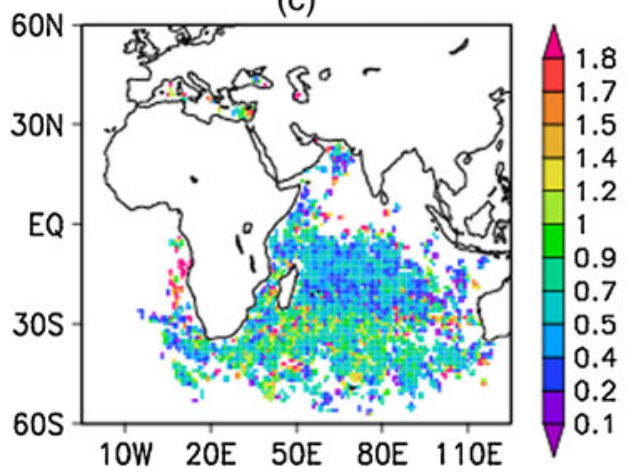

(b)

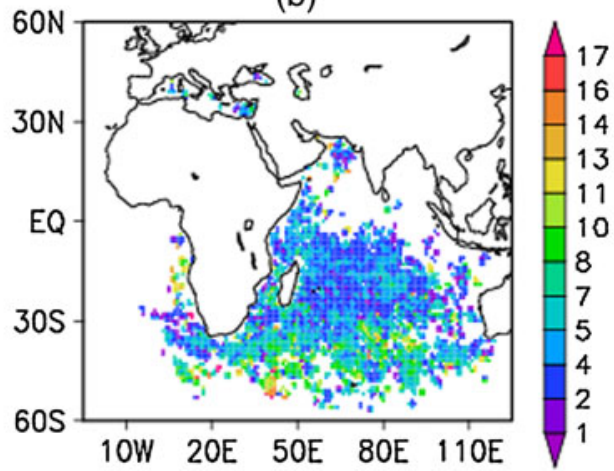

(d)

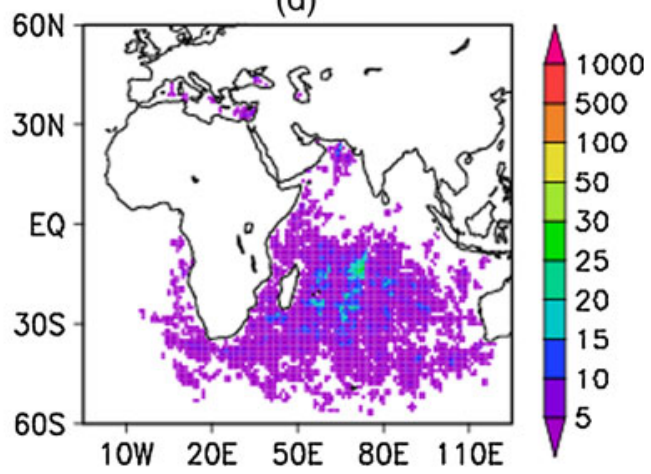

Figure 10. Map plot for Meteosat-7 VIS winds vs. OSCAT winds for July 2010. (a) Bias, (b) MVD, (c) normalized RMS vector difference, and (d) number of collocations.

Table 3. Validation of Kalpana-1 derived LR VIS winds with Meteosat-7 derived HR VIS winds. Normalized RMSVD is dimensionless. All other units are in $\mathrm{m} / \mathrm{s}$.

\begin{tabular}{lc}
\hline Parameter & $\begin{array}{c}\text { Kalpana-1 LR vs. } \\
\text { Meteosat-7 HR winds }\end{array}$ \\
MVD & 3.15 \\
Normalized RMSVD & 0.31 \\
RMSVD & 3.40 \\
Standard deviation & 0.96 \\
Bias & -0.03 \\
Mean Kalpana-1 wind speed & 11.13 \\
\hline
\end{tabular}

It may be noted that the density of observations for this region is quite low. Out of all the available observations, it is found that the maximum faltering cases occurred around 11 UTC throughout the month. A closer inspection yields retrieved winds twice as faster as the model estimates. As a case study, the 'problem vectors' are plotted (figure 6a-b) with the GFS collocated observations over the VIS and IR image valid at 11 UTC of 31 July 2010. It shows that vectors disagree in speed and direction with the background and suggest strong wind vectors. These vectors are more appropriately a part of the easterly jet stream which has been wrongly assigned a height too low. In tropics, strong winds often blow out cirrus plumes into long tails at heights around $200 \mathrm{hPa}$. Tracers from these plumes give a quite faithful representation of the wind motion. The analysis of the derived winds over VIS and IR imagery reflects tracking of faint cirrus plumes. This inconsistency in the height assignment is a major contribution towards high speed bias and hence high MVD over northern Indian Ocean. LR VIS winds lying between 850 and $975 \mathrm{hPa}$ are also validated with OSCAT winds. Figure $7(\mathrm{a}-\mathrm{d})$ shows the error analysis map for the same. Validation with the OSCAT winds gives an MVD of around $4.76 \mathrm{~m} / \mathrm{s}$ and bias of $1.78 \mathrm{~m} / \mathrm{s}$ is observed (table 2).

Due to low accuracy of HR Kalpana-1 VISwinds, retrieval with Meteosat-7 HR VIS imagery is also attempted. Meteosat-7 VIS image has a resolution of $2.5 \mathrm{~km}$ at sub-satellite point. Wind vectors are derived using $24 \times 24$ pixel windows with each vector representing an area of $60 \mathrm{~km} \times$ $60 \mathrm{~km}$. These high resolution winds are derived using the same procedure as for the Kalpana1 winds. Table 1 enlists the statistics on validation with collocated GFS winds for July 2010. 
(a)

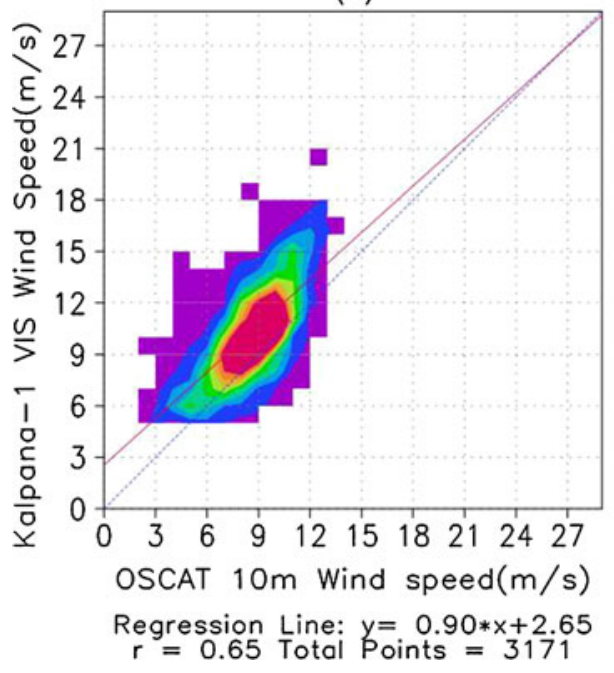

(b)

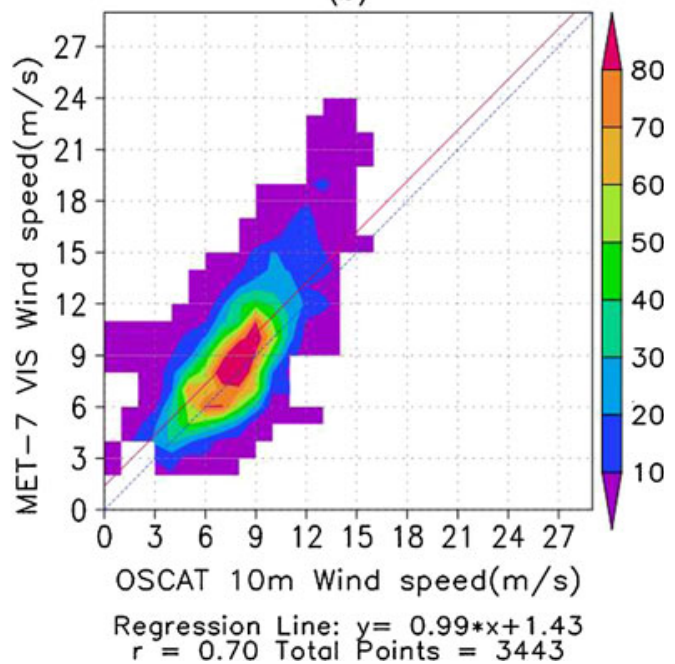

Figure 11. (a) O-B density plot for Kalpana-1 LR VIS winds vs. OSCAT winds and (b) same as (a) but for Meteosat-7 VIS winds.

(a)

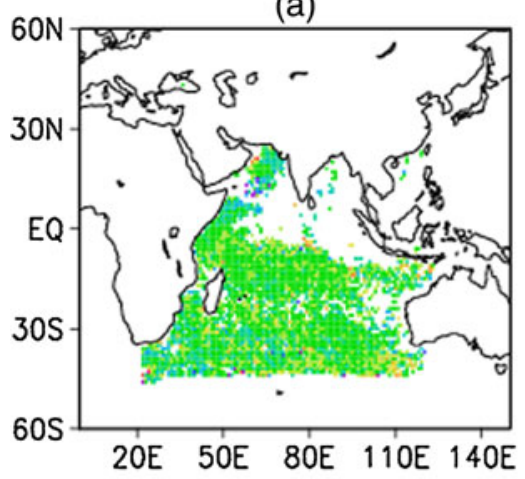

(c)

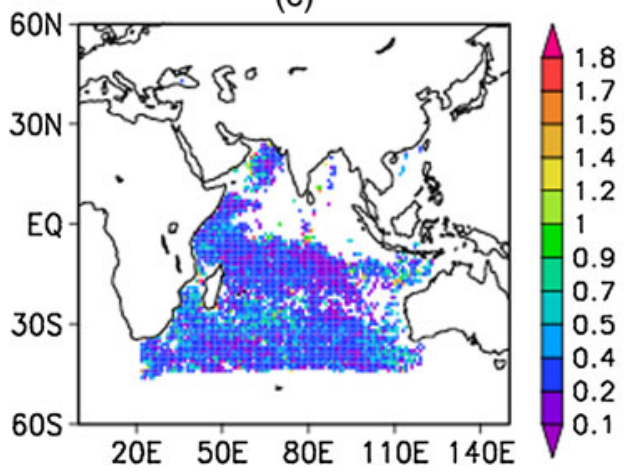

(b)

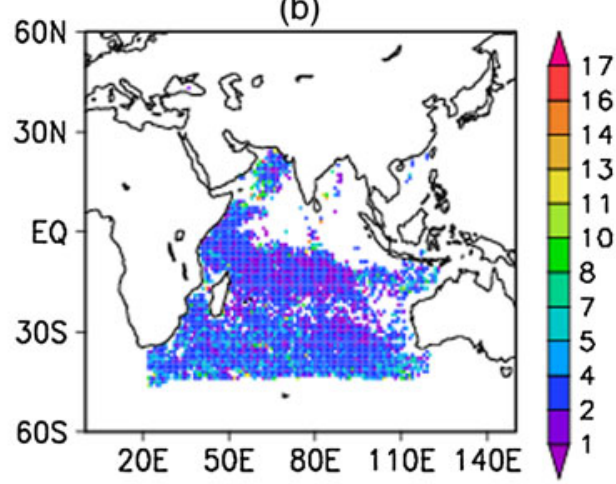

(d)

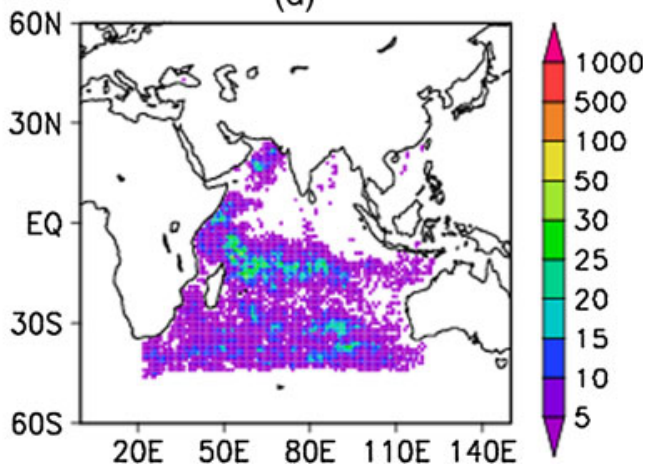

Figure 12. Map plot for Kalpana-1 LR VIS winds vs. Meteosat-7 VIS winds for July 2010. (a) Bias, (b) MVD, (c) normalized RMS vector difference, and (d) number of collocations.

Figure $8(\mathrm{a}-\mathrm{d})$ shows the corresponding spatial error analysis map. For a large part of the Indian Ocean region, the mean vector difference varies from 2 to $6 \mathrm{~m} / \mathrm{s}$. Also the correlation between background and observations is observed to be 0.81 (figure 9). Meteosat-7 VIS winds are also validated against collocated OSCAT winds. An MVD of $5.26 \mathrm{~m} / \mathrm{s}$ and a positive bias of $1.33 \mathrm{~m} / \mathrm{s}$ are observed (table 2). The Meteosat-7 VIS winds and Kalpana-1 LR VIS winds show almost identical results on comparison with the OSCAT winds, due to almost identical retrieval algorithm followed for 


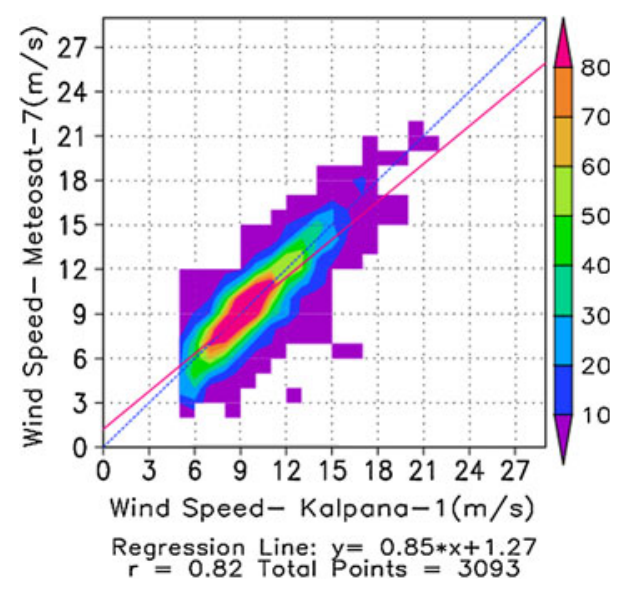

Figure 13. O-B density plot for Kalpana-1 LR VIS winds vs. Meteosat-7 VIS winds for July 2010.

both. Figures 10 and 11(b) give the map and the scatter plot for the comparison. A correlation of 0.70 between the two is observed.

The LR Kalpana-1 winds are also compared with the collocated HR Meteosat- 7 winds. Due to almost identical retrieval algorithm, a low MVD of $3.15 \mathrm{~m} / \mathrm{s}$ is observed. Table 3 shows the validation statistics. The observations from two satellites also show a strong correlation of 0.82 (figure 13). Figure 12 gives the map plot for the same. Difference in the coverage area of both the satellite restricts the area of comparison to the Indian Ocean region.

\section{Conclusions}

Low level winds are retrieved from tracking clouds in Kalpana-1 VIS images. Each wind represents an area of $120 \mathrm{~km} \times 120 \mathrm{~km}$ at sub-satellite point. The retrieval of winds from full resolution VIS image is also tried but due to navigational and registration issues, the quality of high resolution VIS winds is poor though each wind corresponds to an area of $30 \mathrm{~km} \times 30 \mathrm{~km}$ in full resolution. For better accuracy and hence further usage in NWP models, the retrieval from IR equivalent VIS Image is pursued. In comparison to IR image, VIS image produces marginally more winds due to better contrast but no winds are retrieved over land. The wind vectors retrieved are validated against GFS model winds and OSCAT winds valid at the retrieval time. For July 2010, the MVD is observed to be around $5.24 \mathrm{~m} / \mathrm{s}$ when validated with GFS model winds, while validation with OSCAT winds shows MVD of $4.76 \mathrm{~m} / \mathrm{s}$. The same comparison of Meteosat-7 VIS winds with GFS model winds and OSCAT winds also shows MVD values of 5.11 and $5.26 \mathrm{~m} / \mathrm{s}$, respectively. The comparison of Kalpana-1 VIS winds with that of Meteosat-7 VIS winds shows MVD value of $3.15 \mathrm{~m} / \mathrm{s}$. This limited validation ensures the quality of Kalpana-1 VIS winds for its use in operational NWP. Presently, VIS winds are produced operationally every half hour from sunrise to sunset (local time). Usage of visible winds is limited to day-time and also the processing area migrates throughout the day.

\section{Acknowledgements}

The authors thank the anonymous reviewers for their critical and insightful comments/valuable suggestions, which were helpful in substantially improving the content and quality of presentation of this manuscript. The OSCAT Operational Standard Data Products are produced and distributed by National Remote Sensing Centre (NRSC: www.nrsc.gov.in). The authors would like to thank National Centers for Environmental Prediction (NCEP) for GFS Model analysis data and EUMETSAT (http://archive.eumetsat.int/, http://eportal.eumetsat.int) for providing METEOSAT-7 data. The Kalpana-1 data was sourced from MOSDAC (www.mosdac.gov.in). The authors are also thankful to the Director, Space Applications Centre, Indian Space Research Organisation and Deputy Director EPSA for their encouragement.

\section{References}

Deb S K, Kishtawal C M, Pal P K and Joshi P C 2008 A modified tracer selection and tracking procedure to derive winds using water vapor imagers; J. Appl. Meteor. Climatol. 47 3252-3263.

Deb S K, Kishtawal C M, Kaur I, Pal P K and Kumar A S K 2012 Multiplet based technique to derive atmospheric winds from Kalpana-1; In: Proc. 11th International Wind Workshop February 20-24, Auckland, New Zealand.

Forsythe Mary and Doutriax-Boucher 2005 Second analysis of data displayed on NWP SAF AMV monitoring Website; NWP SAF Technical Report 20.

Fujita T 1968 Present status of cloud velocity components from ATS-1 and ATS-3; COSPAR Space Res. 9 $557-570$.

Gohil B S, Sarkar A and Agarwal V K 2008 A new algorithm for wind vector retrieval from scatterometer; IEEE Geosci. Rem. Sens. Lett. 5 387-391.

Hayashi Masahiro 2012 Recent status and development of atmospheric motion vectors at JMA; In: Proc. 11th International Wind Workshop Febuary 20-24, Auckland, New Zealand.

Holmlund K L, Marie Doutriax-Boucher and Carranza M 2012 Current status of EUMETSAT operational winds; In: Proc. 11th International Wind Workshop Febuary 20-24, Auckland, New Zealand.

Hongmiong Q, Irwing A, Pennoyer W, Augembaum J and Zhang D 2010 Operational wind products at NOAA/NESDIS: A status report; In: Proc. 10th Int. Winds Workshop, Febuary 22-26, 2010, Tokyo, Japan. 
Hubert L F and Whitney L F Jr 1971 Wind estimation from geostationary satellite pictures; Mon. Weather Rev. 99 665-672.

Kelly G 2004 Observing system experiments of all main data types in the ECMWF operational system; In: Proc. 3rd WMO Numer. Weather Prediction OSE Workshop, Alpbach, Austria, 32-36, WMO Tech Rep., 1228.

Kishtawal C M, Deb S K, Pal P K and Joshi P C 2009 Estimation of atmospheric motion vectors from Kalpana-1 imagers; J. Appl. Meteorol. Climatol. 48(11) 2410-2421.

Le Marshall J, Pescod N, Khaw A and Allen G 1993 The real time generation and application of cloud drift winds in the Australian region; Aust. Meteor. Mag. 42 89-103.

Nash J E and Sutcliffe J V 1970 River flow forecasting through conceptual models. Part I: A discussion principles; J. Hydrol. 10(3) 282-290.

Ottenbacher Andreas, Maria Tomassini, Kenneth Holmlund and Johannes Schmetz 1997 Low-level cloud motion winds from Meteosat High-Resolution Visible Imagery; Wea. Forecast. 12 175-184.
Oyama R 2010 Recent upgrades of and activities for atmospheric motion vectors at JMA/MSC; Proc. 10th Int. Winds Workshop, Febuary 22-26, Tokyo, Japan.

Qisong Z, Jianmin X, Xiaohu Z, Sujuan W, Gang M, Xiuquing H, Peng Z, Yong Z, Hua Z and Guiqing L 2010 Status of operational AMVs from FY-2 satellites; Proc. 10th Int. Winds Workshop, Febuary 22-26, Tokyo, Japan.

Rodgers E, Gentry R C, Shenk W and Oliver V 1979 The benefits of using short interval satellite images to derive winds for tropical cyclones; Mon. Weather Rev. 107 $575-584$.

Sohn Eunha, Sung-Rae Chung and Jong-Seo Park 2012 Current staus of COMS AMV in NMSC/KMA; In: Proc. 11th International Wind Workshop Febuary 20-24, Auckland, New Zealand.

Uchida H, Oshima T, Hamada T and Osano S 1991 Lowlevel cloud motion wind field estimated from GMS short interval images intyphoon vicinity; Geophys. Mag. 44 $37-50$. 